Disponível em

http://www.anpad.org.br/rac

RAC, Rio de Janeiro, v. 19, $3^{\text {a }}$ Edição Especial, art. 5, pp. 328-347, Outubro 2015

http://dx.doi.org/10.1590/1982-7849rac20151922

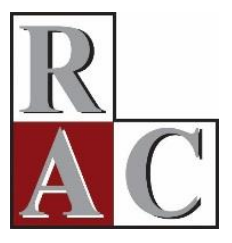

\title{
Explorando Aspectos Indígenas da Gestão Numa Organização Financeira: Jeitinho e Sociedade Relacional
}

Exploring Indigenous Management Aspects in a Financial Organization: Jeitinho and Relational Society

Ricardo Antonio Fernandes Universidade Presbiteriana Mackenzie

Darcy Mitiko Mori Hanashiro Universidade Presbiteriana Mackenzie

Artigo recebido em 03.04.2014. Última versão recebida em 02.02.2015. Aprovado em 02.02.2015. Publicado online em 21.08.2015. 


\title{
Resumo
}

Há um crescente interesse de pesquisadores em compreender conceitos localmente relevantes, e não importados de outras culturas, chamado de abordagem indígena de gestão (indigenous management). Seguindo essa linha de pensamento, este artigo realizou uma análise da literatura socioantropológica e de estudos organizacionais sobre a cultura brasileira, que resultou em uma síntese de cinco traços característicos da nossa sociedade: Hierarquia, Ambiguidade, Malandragem, Jeitinho e Sociedade Relacional. Com foco em dois traços: Jeitinho e Sociedade Relacional, o artigo buscou identificar e analisar a incidência de ambos na gestão de uma organização financeira. Um questionário, com escalas do tipo Likert, foi desenvolvido e aplicado em uma amostra de 303 funcionários. Os resultados evidenciaram o Jeitinho descrito por uma estrutura de três dimensões: contorno de regras, flexibilização e estratégia informal de resolução de problemas. A Sociedade Relacional, por sua vez, foi composta por quatro dimensões: pessoalidade, relações afetivo-familiares, predominância da confiança sobre as relações impessoais e predominância do relacionamento pessoal sobre o profissional. Independentemente de variáveis sociodemográficas, o Jeitinho foi identificado como uma prática social comum, e a Sociedade Relacional como um ambiente que favorece a utilização do Jeitinho.

Palavras-chave: jeitinho; sociedade relacional; cultura brasileira; abordagem indígena de gestão; abordagem emic.

\begin{abstract}
There is an increasing interest from researchers to understand concepts which are meaningful for our own society, and not imported from other cultures, called indigenous management approaches. Following this line of research, this article carried out a socio-anthropological literature analysis in the field of organizational studies on Brazilian culture which resulted in a synthesis of five distinctive traits of our society: Hierarchy, Ambiguity, Trickery (Malandragem), Jeitinho and Relational Society. The article focused on Jeitinho and Relational Society and aimed to identify and analyze the incidence of both traits, in the management of a financial organization. A questionnaire, using a Likert scale, was developed and applied to a sample of 303 employees from such an organization. Jeitinho can be described through a three-dimensional structure: circumvent rules, flexibility and an informal problemsolving strategy. The Relational Society, also a multidimensional construct, was composed of personal relationships, familiar-affective relations, trust-dominance over impersonal relations and personal relationship dominance over professional ones. Regardless of the socio-demographic variables, Jeitinho was identified as a common social practice and Relational Society was seen as an environment that favors the use of Jeitinho.
\end{abstract}

Key words: jeitinho; relational society; Brazilian culture; indigenous management approach; emic approach. 


\section{Introdução}

No Brasil, a partir da década de 1990, surgiram estudos que, apoiados primariamente na formação histórica, cultural, econômica e social do país, procuraram mostrar as implicações da cultura brasileira para o gerenciamento das organizações. Alcadipani e Crubellate (2003) constataram que vários trabalhos sobre cultura brasileira apontam a presença de traços culturais nítidos e decifráveis que afetam as organizações no país, formando uma cultura organizacional brasileira (Motta, 1997). Barros e Prates (1996), com base em uma pesquisa quantitativa com 2500 executivos, discutem o estilo brasileiro de administrar. Um estudo empírico realizado por Chu (2010) revelou os traços culturais que caracterizam o Modelo Contemporâneo de Gestão à Brasileira pós-globalização.

Esses estudos refletem a importância das estruturas de referências locais e indígenas, além de categorias culturalmente derivadas (Berry, Poortinga, Segall, \& Dasen, 2002), em contraposição às práticas gerenciais dominantes, mainstream e universais.

Nesses estudos, o Jeitinho apareceu como um traço distintivo da cultura brasileira. No Brasil, foi foco tanto de pesquisas teóricas (Campos, 1976; Ramos, 1966; Torres, 1973) como empíricas (Abreu Vieira, Costa, \& Barbosa, 1982; Almeida, 2007; Amado \& Brasil, 1991; Barbosa, 1987, 2006; DaMatta, 1978; Prado, 2005), que contribuíram para aprofundar conceitualmente esse traço cultural.

Pesquisadores estrangeiros também se debruçaram sobre a temática do Jeitinho no Brasil. Rosenn (1971) promoveu um estudo minucioso sobre a prática do Jeitinho; Duarte (2006) explorou o Jeitinho como uma estratégia informal de solução de problemas nas organizações brasileiras. Em outro estudo, Duarte (2011) investigou o papel estratégico do charme e da simpatia. Nesta linha, Barbosa (2006) identificou uma forte ligação entre charme e simpatia, aspecto essencial para criar uma relação positiva que possibilite a prática bem sucedida do Jeitinho.

À luz de DaMatta (1978), o Brasil caracteriza-se como uma sociedade relacional em que "instituímos o sistema de relações pessoais como um dado estrutural da nossa sociedade" (p. 192), na qual as relações entre os indivíduos se mostram mais importantes que os próprios indivíduos. A prática do Jeitinho, portanto, ajusta-se plenamente com uma sociedade sob a predominância da perspectiva relacional, fecundada em suas raízes históricas.

No campo dos estudos cross-cultural, gestão internacional e gestão comparada, pesquisadores têm devotado crescente atenção empírica e teórica à prática do Jeitinho. Eles salientam o Jeitinho como um aspecto indígena de gerenciamento, prática enraizada na cultura do país em contraposição às práticas gerenciais dominantes euro-americanas (Balbinot, Minghini, \& Borim-de-Souza, 2012; McCarthy, Puffer, Dunlap, \& Jaeger, 2012; Smith, 2008; Smith, Huang, Harb, \& Torres, 2012) conhecidas como mainstream.

Recentemente, no Brasil, pesquisadores oriundos da psicologia social têm-se interessado em aprofundar a compreensão do Jeitinho como construto psicológico indígena por meio de pesquisas qualitativas (Pilati, Milfont, Ferreira, Porto, \& Fischer, 2011) e quantitativas (Ferreira, Fischer, Porto, Pilati, \& Milfont, 2012).

Considerando a origem da prática do Jeitinho no formalismo (Ramos, 1966), sua sustentação numa sociedade relacional (DaMatta, 1978) e seu caráter universal (Barbosa, 2006), é oportuno investigar a presença desses traços no contexto das organizações burocráticas, nas quais predomina uma forma de dominação racional-legal, ambiente pouco contemplado nas pesquisas nacionais e internacionais. As burocracias "são sistemas sociais formais, impessoais e dirigidos por administradores profissionais, que tendem a controlá-los cada vez mais completamente" (Motta \& Bresser Pereira, 1984, p. 29). Reflexionando sobre esse ambiente, surgem duas indagações: o Jeitinho e as características de uma sociedade relacional fazem parte do cotidiano organizacional? Em que extensão, em áreas de análise e controle de negócios de uma instituição financeira privada nacional, esfera pesquisada neste 
estudo, os gestores reconhecem a prática do Jeitinho e as soluções baseadas em relacionamentos pessoais?

Problematizações como essas instigaram a realização de uma pesquisa quantitativa com o objetivo geral de identificar e analisar a incidência dos traços Jeitinho e Sociedade Relacional na gestão de uma instituição financeira nacional privada. Dois objetivos específicos foram definidos: (a) analisar se esses traços manifestam-se de forma diferente segundo sexo, idade, cargo, escolaridade e tempo de empresa; e (b) analisar a relação entre Jeitinho e Sociedade Relacional. Para o alcance dos objetivos, foi desenvolvida uma escala que mensura os dois traços analisados neste trabalho.

O artigo está estruturado em quatro seções, além desta introdução. A primeira seção resgata o background histórico sobre as características culturais brasileiras, e traz uma breve contextualização sobre a abordagem indígena de gestão. A segunda seção apresenta os procedimentos metodológicos, incluindo a construção da escala, as técnicas estatísticas utilizadas e a amostra pesquisada. A terceira tem por foco a análise e a discussão de resultados. Por fim, são tecidas algumas considerações, as implicações teóricas e práticas da pesquisa, suas limitações e sugestões para futuros estudos.

\section{As Raízes Sócio-Históricas da Cultura Brasileira: Dialogando com Freyre, Holanda, Ribeiro e DaMatta}

Na obra clássica de Freyre (2004), os centros econômico, social e político são analisados por meio das relações presentes em Casa Grande e Senzala. Esses dois polos reproduzem os sistemas de produção (monocultura latifundiária), de trabalho (escravo), religioso (catolicismo), familiar, político (compadrismo) e da vida sexual (patriarcalismo polígamo).

Nesse cenário, os senhores rurais eram os donos do poder: além de possuidores de terras, verdadeiros feudos, eram também proprietários de homens e mulheres que trabalhavam para eles, sobre os quais possuíam poder de vida e morte. A relação vigente parece ter sido a de obediência e lealdade em troca de proteção.

A estrutura social da Casa Grande é a de uma família formada pelo patriarca, sua esposa oficial, suas mucamas e os filhos legítimos e ilegítimos. Nesse contexto, em que não havia regras que não pudessem ser alteradas a qualquer instante pelo patriarca, percebe-se a necessidade dos demais integrantes de manter boas relações com o poder, encarnado na figura desse chefe de família, valorizando, sobremaneira, a força do caráter relacional para a sobrevivência na sociedade. A análise da obra de Freire evidencia a estrutura da sociedade colonial caracterizada por uma relação paternalista, autoritária e hierarquizada.

A herança portuguesa é evocada na obra Raízes do Brasil (Holanda, 1995). Nas relações sociais valem critérios subjetivos, de simpatia e antipatia, balizadas pelo crivo pessoal e familiar. Nesse livro, destaca-se a adaptabilidade dos portugueses aos trópicos e a importância de seu caráter aventureiro no sucesso da colonização e na diversidade brasileira. A influência do colonizador português na formação cultural do Brasil é maior para Holanda do que para Freyre. Portugal seria uma terra em que todos são ou acreditam ser fidalgos, o que resulta em frouxidão no acordo coletivo e nas formas de organização.

O caráter personalista de nossa sociedade seria proveniente de "uma suavidade dengosa e açucarada que invade, desde cedo, todas as esferas da vida colonial" (Holanda, 1995, p. 60). Esse caráter afetivo, não racional e passional do brasileiro levaria a uma estagnação, ou, antes, a uma atrofia correspondente das qualidades ordenadoras, disciplinadoras necessárias a uma população para organizar-se politicamente.

A cordialidade do brasileiro é apontada como uma característica marcante da nossa sociedade, a ponto de o autor mencionar que "a contribuição brasileira para a civilização será de cordialidade daremos ao mundo o 'homem cordial'. A lhaneza no trato, a hospitalidade, a generosidade, virtudes tão 
gabadas por estrangeiros que nos visitam, representam, com efeito, um traço definido do caráter brasileiro" (Holanda, 1995, p. 146).

Holanda (1995) considerou o espírito aventureiro do português como o elemento orquestrador por excelência de nossa vida nacional. O aventureiro, cujo ideal é obter ganhos com pouco ou nenhum esforço, é o contraponto da figura do trabalhador.

Conforme DaMatta $(1978,1984)$, a identidade do brasileiro é buscada nas irmandades e associações populares, voltadas para fora do sistema. O conceito de pessoa/ indivíduo remete à questão da cordialidade tratada por Holanda (1995). A pessoa estaria sujeita às relações cordiais, pautadas por sentimentos provenientes do coração, do íntimo, familiar e privado. Por sua vez, o indivíduo estaria sujeito à lei pura e simples. Desse modo, observa-se a dificuldade do brasileiro em relacionar-se com leis e regras uma vez em que quase tudo seria baseado em relações de amizade. Esse caráter da sociedade brasileira aparece com clareza na expressão "aos amigos, tudo, aos inimigos, a lei” (DaMatta, 1978, p. 187).

Do mesmo modo, a indagação "sabe com quem está falando?" (DaMatta, 1978, p. 45) remete ao caráter relacional quando usada para mostrar uma identificação social vertical, pois seu uso promove uma hierarquização em situações que deveriam valer as regras impessoais. Essa expressão encontra-se em meio a um embate entre o sistema de leis que deveria valer para todos indistintamente e as relações que permitem um tratamento diferenciado, mas que, no entanto, só valem para quem apresenta tais relações. Como consequência disso, decorre o Jeitinho, ou seja, dessa inadequação entre as leis e a sua prática social.

Para DaMatta (1978), o Jeitinho pode ser definido como um modo simpático e humano de relacionar o impessoal com o pessoal, ou como um modo legítimo e pacífico de promover a junção entre a lei e a pessoa que a está usando. Para o autor, o Jeitinho consiste em uma estratégia de navegação social, desenvolvida como uma forma de tentar negociar a formalidade excessiva e as restrições legais na sociedade brasileira. Quem usa o Jeitinho precisa exercitar um poder de sedução. Essa habilidade remete à figura do malandro, um profissional na arte do Jeitinho e da sobrevivência em situações adversas, caracterizando "um modo ambíguo de burlar as leis e as normas sociais mais gerais" (DaMatta, 1984, p. 103).

A obra de Ribeiro (2006) contrasta com a noção de uma cultura quase monolítica brasileira, trazendo para discussão a diversidade cultural da sociedade. O autor analisa vários núcleos étnicos com características socioculturais adaptadas às condições locais, sejam ecológicas ou de produção. Os traços observados nos demais autores abordados repetem-se em todos os núcleos tratados por Ribeiro, como a hierarquia rígida entre patrões e empregados, a ambiguidade na observação das leis de acordo com os envolvidos na situação, a busca por relacionamentos (pertencer a um grupo) com a regra de lealdade em troca de proteção e outros.

A partir das leituras e das análise de Freyre (2004), Holanda (1995), DaMatta (1978, 1984) e Ribeiro (2006), foram depreendidos cinco traços centrais da sociedade brasileira: Hierarquia, Ambiguidade, Malandragem, Sociedade Relacional e Jeitinho. Destaca-se que a escolha desses traços obedece a uma lógica de categorização e a fronteira entre um e outro nem sempre é clara.

\section{Traços Brasileiros: Um Olhar dos Pesquisadores na Área de Estudos Organizacionais}

Este tópico aborda o olhar de pesquisadores brasileiros da área de estudos organizacionais sobre os principais traços da nossa cultura, anteriormente depreendidos.

No trabalho de Barros (2003), o entendimento dos traços brasileiros visa à construção de um modelo de gestão baseado em três eixos básicos: poder, relações pessoais e flexibilidade. A partir desses eixos, os traços articulam-se "construindo com arte a "gestão à brasileira"” (Barros, 2003, p. 102). Um 
dos traços centrais do modelo é a Concentração de Poder, cuja origem remonta ao autoritarismo patriarcal, e remete ao traço Hierarquia.

O paternalismo é tratado por Freitas (1997), para explicar a busca por proximidade nas relações em uma sociedade hierarquizada como a brasileira. A Hierarquia teria sido herdada das relações vigentes na família patriarcal durante a época da escravidão.

Barbosa (1996) observa a relação do brasileiro com a hierarquia classificando a sociedade como relacional, ou semitradicional, a qual conjugaria uma visão hierárquica e tradicional do mundo com outra igualitária e individualista. Para os brasileiros, as relações sociais têm maior valor do que os indivíduos que as compõem.

O caráter ambíguo, ponderado anteriormente por Barbosa (1996), revela as relações de trabalho em que predominam a hierarquização e o afeto (Motta \& Alcadipani, 1999). A explicação para esse traço está no fato de que, muitas vezes, as decisões, assim como as regras, não são suficientemente claras, decorrendo daí a necessidade de haver certa margem de manobra (Barros, 2003).

$\mathrm{O}$ traço Malandragem reveste-se de um caráter aventureiro. O personagem malandro tem como característica chave a tendência à aversão ao trabalho manual ou metódico e ser mais sonhador que disciplinado (Freitas, 1997). Na visão do autor, o malandro é alguém com alta capacidade de adaptação e flexibilidade, que consegue sair-se bem na maioria das situações. No entanto, Motta e Alcadipani (1999) apontam uma faceta negativa desse traço, pois indica uma predisposição para tirar vantagem e, consequentemente, prejudicar alguém.

O traço Sociedade Relacional simboliza uma teia social complexa, revelada por personalismo, cordialidade e lealdade. Freitas (1997) observa que o brasileiro manifesta um desejo contínuo de estabelecer intimidade, buscando um elo pessoal nas relações impessoais que deveriam ser cobertas de rigores e formalismos. $\mathrm{O}$ autor aponta, como origem desse comportamento, a herança familiar colonial. Freitas (1997), no entanto, alinha-se com Freyre (2004) no entendimento de que essa seria uma herança dos africanos. A ternura, a bondade e o catolicismo humanista teriam sido contribuições dos negros trazidos para cá. Freitas (1997) corrobora o traço cordialidade (Holanda, 1995) para embasar um comportamento decorrente da expressão de um fundo emotivo rico e transbordante. Barros (2003) argumenta que a atração pessoal é o elemento principal da coesão social, e que o brasileiro tende a querer fazer parte de um grupo importante para obter prestígio e poder.

Motta (1997) faz uma análise psicanalítica da necessidade de relacionamentos pessoais no trabalho, em busca de construir o conceito de uma grande família nesse ambiente. Na visão do autor, quando isso ocorre, a tentativa é de levar, para o âmbito da racionalidade instrumental, terreno dos indivíduos para DaMatta, um pouco da racionalidade substantiva e da afetividade do mundo da casa, terreno das pessoas para DaMatta (1978).

Os achados de Chu e Wood (2008) apontam que os gestores pesquisados "buscam relacionamentos próximos e afetivos no ambiente de trabalho, o que torna os relacionamentos pessoais, por vezes, mais importantes do que as competências técnicas" (p. 979) e que essa forma de atuação revelou-se fundamental para a eficiência e a produtividade do trabalho em grupo.

Motta e Alcadipani (1999) analisaram o Jeitinho como resultado de vários outros traços culturais brasileiros. A raiz do Jeitinho seria o formalismo, porém essa não é a única característica cultural brasileira responsável por esse traço. Também contribuem as características de Sociedade Relacional, da busca por intimidade e da aversão ao confronto, as quais se inter-relacionam e permitem sua existência (Motta \& Alcadipani, 1999).

De acordo com Ramos (1983, p. 287), chama-se de Jeito "o genuíno processo brasileiro de resolver dificuldades, a despeito do conteúdo das normas, códigos e leis. É exatamente o formalismo que acarreta a prática do jeito". Para Campos (1976, p. 19), o "jeito não é uma instituição legal nem ilegal, é 'paralegal'”. 
Barbosa (2006) constatou que as definições de Jeitinho encontradas em sua pesquisa não sofreram variações substanciais e dizem respeito a "uma forma especial de resolver algum problema ou situação difícil ou proibida; ou uma solução criativa para alguma emergência, seja sob a forma de burla a alguma regra ou normas preestabelecidas, seja sob a forma de conciliação, esperteza ou habilidade" (p. 41). Para a autora, o conceito de Jeitinho não é uma categoria claramente definida. Da mesma forma, os resultados empíricos de Almeida (2007) mostraram que os cenários classificados como Jeitinho não apresentam ampla diferença em comparação aos cenários de favor e corrupção. Na pesquisa de Barbosa (2006), o Jeitinho manifestou uma característica universal, sendo usado por todos sem distinção de idade, sexo, profissão ou escolaridade.

Em pesquisa qualitativa, Duarte (2011) explora o papel estratégico do charme e da simpatia, aspectos da Sociedade Relacional, e sua relação com o Jeitinho. A autora conclui que essas práticas sociais não são unicamente brasileiras. Entretanto, encontrou evidências que brasileiros atribuem uma importância particular a elas no dia a dia.

O Jeitinho é percebido de forma negativa para o país na pesquisa de Chu e Wood (2008), tratandose de um "comportamento pouco profissional ou até mesmo amador. Gera para o país um sentimento de instabilidade e de falta de credibilidade nas instituições que o governam" (p. 979). Entretanto, é benéfico individualmente para as pessoas que conseguem obter vantagens por meio de contorno das regras formais (Chu, 2010).

\section{Formalismo, Jeitinho e Sociedade Relacional}

Para compreender o significado do Jeitinho, convém retomar a sua origem. Ramos (1966) elucida o conceito de formalismo a partir da concepção de Riggs (1964 como citado em Ramos, 1966). Para compreender o formalismo, recorre-se aos três modelos puros e hipotéticos de sociedade definidos pelo autor: a concentrada, modelo mais tradicional, que remete a uma só estrutura social; a difratada, no outro extremo, na qual a cada estrutura corresponderia uma função distinta (o mais difratado sistema social seria os Estados Unidos) e, por fim, o modelo prismático, que se situa entre os outros dois modelos. Para Riggs (1964 como citado em Ramos, 1966), a sociedade prismática "apresenta alto grau de heterogeneidade, uma vez que nela coexistem o antigo e o moderno, o atrasado e o avançado, o velho e o novo" (p. 332), tanto na forma material quanto na conduta humana. Diversamente, a sociedade concentrada e a difratada apresentam alto grau de homogeneidade, pois as práticas e os sistemas vigentes são mais coerentes.

Além da heterogeneidade, o critério de superposição é avaliado por Riggs (1964 como citado em Ramos, 1966). Consiste no exercício cumulativo de funções diferentes para a mesma unidade social. Nas sociedades prismáticas, embora as funções sejam formalmente atribuídas a distintas unidades sociais, na prática, os critérios familiares e de compadrio influenciam no trabalho administrativo. $\mathrm{O}$ autor sustenta que a superposição e a heterogeneidade são fenômenos ligados ao formalismo, o qual é dominante nas sociedades prismáticas e mínimo nas concentradas e difratadas.

Riggs (1964 como citado em Ramos, 1966) define o formalismo como "a discrepância entre a conduta concreta e a norma prescrita que se supõe regulá-la. Registra-se ali onde o comportamento efetivo das pessoas não observa as normas estabelecidas que lhe correspondem, sem que disso advenham sanções para os infratores" (p. 333).

Pela análise empírica de Riggs (1964 como citado em Ramos, 1966), a sociedade brasileira apresenta contornos de um modelo prismático em que a heterogeneidade e a superposição lhe são peculiares e, juntas, engendram o formalismo. Como demonstrado por Ramos (1983, p. 287), "é o formalismo que acarreta a prática do Jeito". O formalismo é uma estratégia primária, enquanto o jeito é uma estratégia de segundo grau, isto é, suscitada pelo formalismo, argumenta o autor. 
A partir do sentido estratégico do formalismo nas sociedades prismáticas, como a brasileira, e da sistematização da literatura abordada evidenciando dois aspectos - o caráter coletivo dos traços Jeitinho e Sociedade Relacional e uma inter-relação entre eles, destacam-se três hipóteses:

Hipótese 1: Jeitinho não difere significativamente por (a) sexo, (b) idade, (c) nível hierárquico, (d) escolaridade e (e) tempo de empresa dos respondentes;

Hipótese 2: O Sociedade Relacional não difere significativamente por (a) sexo, (b) idade, (c) nível hierárquico, (d) escolaridade e (e) tempo de empresa dos respondentes;

Hipótese 3: Há relação positiva entre as dimensões de Jeitinho e as dimensões de Sociedade Relacional.

\section{Jeitinho e Sociedade Relacional: Aspectos Indígenas de Gestão}

A etimologia da palavra indígena, originária do latim, designa natural do lugar em que vive, gerado dentro da terra que lhe é própria (Houaiss, n.d.).

A compreensão de práticas gerenciais chamadas indígenas (indigenous management) parece ser uma preocupação relativamente recente de pesquisadores do management, cujos fundamentos derivam de uma área pouco conhecida que é a psicologia indígena.

Sinha (1997) pontua quatro linhas subjacentes na definição da psicologia indígena. Primeiro, o "conhecimento psicológico não é para ser externamente imposto" (p. 132). Em vez disso, a tradição cultural deveria sustentar esse conhecimento. Segundo, "a verdadeira psicologia reside não em comportamento artificialmente induzido (experimentalmente planejado), mas em atividades mundanas e diárias das pessoas" (p. 132). Terceiro, "o comportamento é para ser entendido e interpretado não na forma de categorias importadas e teorias estrangeiras (imposição etics), mas com base em estruturas de referências locais e indígenas e categorias culturalmente derivadas" (p. 132) (ver Berry et al., 2002). Quarto, psicologia indígena incorpora conhecimento psicológico que é relevante e é designado para seu povo (pessoas). Em outras palavras, ela reflete a realidade sociocultural de sua sociedade.

Adaptando esse conhecimento ao management, a abordagem indígena de gerenciamento nas organizações se caracterizaria por adotar conhecimento derivado de estruturas de referências locais, não externamente imposto e nem induzido artificialmente. Portanto é uma abordagem construída a partir da cultura local, e relevante para o local específico, além de ser apropriada para seu contexto. Isso significa uma contraposição às práticas gerenciais dominantes, mainstream e universais. Logo, entendemos que Jeitinho e Sociedade Relacional são construtos indígenas brasileiros, pois referem-se a aspectos nativos, não importados, culturalmente distintivos, com raízes na formação sócio-histórica do país e cuja prática social conta com o reconhecimento dos brasileiros. Smith, Huang, Harb e Torres (2012) consideram o Jeitinho como um processo de influência informal brasileiro, tal como o guanxi na cultura chinesa e o wasta nas nações árabes, embora sejam construtos indígenas diferentes.

\section{Procedimentos Metodológicos}

Considerando que os traços foram depreendidos por meio de uma análise histórica, cultural e social da formação da sociedade brasileira, isso significa que a abordagem utilizada caracteriza-se como do tipo emic em contraposição à etic. Seguindo definição de Smith (2008), uma estratégia etic é amplamente entendida como aquela cujo foco está no processo sem observar o contexto, enquanto a abordagem emic enfatiza o relacionamento do processo com o contexto em que o mesmo ocorre. 
O constructo Jeitinho foi formulado com base nos traços Formalismo e Flexibilidade, adotandose como definição conceitual: (a) Uma solução legítima para a resolução de problemas causados pela inadequação das regras à prática social, ou seja, o formalismo (DaMatta, 1978, 1984; Ramos, 1983); e (b) Uma forma especial de resolução de problemas ou situações emergenciais usando sensibilidade, habilidade e humildade (no caso do solicitante do Jeitinho), mesmo que, para isso, seja burlada alguma regra (Barbosa, 2006).

É esperado que um praticante do Jeitinho perceba: (a) A existência de regras inadequadas à prática social; (b) A necessidade de flexibilização na aplicação das regras; (c) A necessidade de contornar regras visando resolver problemas ou situações especiais; e (d) A necessidade de ajudar alguém ou dar andamento ao trabalho como sendo prioritária, mesmo que regras tenham que ser contornadas.

Para o constructo Sociedade Relacional, baseado no traço Lealdade às pessoas, adotou-se a seguinte definição conceitual: (a) A confiança é o principal atributo valorizado entre os membros (Ramos, 1983); (b) Após o estabelecimento das relações de amizade entre as pessoas, as obrigações pessoais se impõem acima da norma impessoal, abstrata e legal (Barbosa, 2006); (c) Busca-se manter relacionamentos baseados na afetividade em situações que poderiam pautar-se pela impessoalidade dos agentes (Holanda, 1995).

É esperado que a manifestação do traço Sociedade Relacional seja percebida da seguinte forma: (a) As pessoas procuram estabelecer relacionamentos pessoais no trabalho; (b) As pessoas procuram estabelecer relações pessoais com seu chefe; (c) $\mathrm{O}$ ambiente de trabalho é uma extensão do ambiente familiar; (d) As relações impessoais tendem a dar lugar às relações de confiança (pessoais); (e) $\mathrm{O}$ trabalho é mais produtivo quando realizado com pessoas com as quais há um relacionamento pessoal.

\section{Construção do questionário}

Fundamentado na literatura apresentada, desenvolveu-se um questionário composto por 13 itens para medir o constructo Jeitinho, e 16, para o constructo Sociedade Relacional. Esses itens formam indicadores reflexivos das variáveis latentes Jeitinho e Sociedade Relacional, que não podem ser mensurados diretamente (MacKenzie, Podsakoff, \& Jarvis, 2005).

Os itens são sentenças afirmativas e assumiram o formato do tipo Likert com opções de resposta variando de 1-Discordo Totalmente a 6-Concordo Totalmente. Após a elaboração e revisões feitas pelos autores, o questionário foi pré-testado quanto à validade de conteúdo (Netemeyer, Bearden, \& Sharma, 2003) por três alunos de mestrado e dois de doutorado. Posteriormente, foi realizado o pré-teste quanto à validade de face por cinco profissionais, com perfil semelhante ao da amostra final, que analisaram o instrumento quanto à clareza dos itens, à relevância dos mesmos e à adequação da linguagem à instituição financeira pesquisada. Como resultado, vários termos foram ajustados ou substituídos.

Um terceiro pré-teste foi realizado para avaliar se os itens apresentariam bons resultados do ponto de vista psicométrico (cargas fatoriais, variância extraída e confiabilidade). Ele foi conduzido com 128 alunos dos cursos de Pós-Graduação Lato Sensu de uma Universidade da cidade de São Paulo.

Uma análise fatorial exploratória foi realizada com os itens de Jeitinho e outra com os itens de Sociedade Relacional. Optou-se pela extração dos componentes principais com rotação oblíqua Promax (Hair, Anderson, Tathan, \& Black, 2005).

As análises para testar o ajuste entre os dados e a análise fatorial executada basearam-se no Teste Bartlett de Esfericidade, na Medida de Kaiser-Meyer-Olkim (KMO), na observação do scree plot, na variância total extraída e na confiabilidade (DeVellis, 2003; Hair et al., 2005).

A análise fatorial dos 13 itens de Jeitinho revelou três fatores, com variância total extraída de $52,5 \%$. Foram eliminados quatro itens por apresentarem cargas fatoriais muito baixas, sendo que dois deles formaram um fator com alfa de Cronbach igual a 0,35. Com isso, a escala resultou em 9 itens. 
Os textos sobre processo de desenvolvimento de escalas recomendam que itens que possuem baixa correlação item-total, devem ser eliminados para aumentar a confiabilidade da escala. Essa recomendação é apropriada no caso de indicadores reflexivos, pois os itens são todos provenientes de um mesmo domínio de conteúdo, como são os itens de Jeitinho e Sociedade Relacional (MacKenzie et al., 2005).

A análise fatorial dos 16 itens de Sociedade Relacional revelou seis fatores, com variância explicada de $64,2 \%$. Quatro itens foram eliminados por apresentarem cargas fatoriais muito baixas, sendo que três deles formaram um fator com alfa de Cronbach igual a 0,545, gerando uma escala com 12 itens.

\section{Coleta de dados: população e amostra}

A organização em que foi realizada a pesquisa é uma instituição financeira privada nacional de grande porte. Após consulta às áreas da empresa, oito, que pertencem ao escritório central da organização, concordaram em participar da pesquisa. Assim, o método adotado foi do tipo não probabilístico, pois a seleção não foi aleatória e sim por conveniência. Tal fato inviabiliza a generalização dos resultados.

Todos os respondentes estavam fisicamente localizados em um mesmo conjunto de edifícios e trabalhavam em áreas administrativas que atuam como suporte das áreas de negócios. Na carta-convite, foram mencionados o tempo estimado de resposta ao questionário ( 8 minutos); a inexistência de respostas certas ou erradas; a garantia de anonimato e o tratamento consolidado dos dados.

Dos 833 questionários impressos e entregues, 321 foram respondidos $(38,5 \%)$. A limpeza do banco de dados resultou na eliminação de 18 questionários por apresentar valores faltantes em todas as variáveis sociodemográficas ou em vários itens de Jeitinho e Sociedade Relacional. Dentre os 303 questionários restantes, 16 apresentavam valor faltante em uma das questões e quatro em duas das questões. Estes casos foram mantidos e os valores faltantes foram substituídos pela média de todas as respostas válidas para aquela questão (Hair et al., 2005). Por fim, foi feita a verificação de observações atípicas univariadas (Hair et al., 2005), optando-se por manter todos os respondentes para a análise fatorial.

A amostra final de 303 respondentes caracterizou-se por 56,1\% de mulheres, idade média de 31,8 anos e tempo médio na empresa de 8,4 anos. Nenhum respondente tinha nível inferior ao ensino médio, sendo que 74,6\% possuem superior completo ou Pós-Graduação (completo ou incompleto). Dentre as áreas pesquisadas, estavam a diretoria de riscos, com $29,9 \%$ dos respondentes, a área de suporte a operações de crédito imobiliário, com 39,3\%, e a área de suporte a operações da seguradora, com 25,2\%.

Para diagnosticar se o viés do método comum (common method bias) estava presente, foi utilizado o teste de fator único de Harman (Podsakoff, MacKenzie, Lee, \& Podsakoff, 2003). A partir da análise de componentes principais com todos os 21 itens, obtiveram-se sete componentes com autovalor superior a 1,0, e o primeiro componente principal não rotacionado extraiu apenas $22,6 \%$ da variância, de onde se conclui que o viés do método comum não é uma preocupação na presente escala, pois não emergiu um fator expressivo que explicasse a maior parte da variância.

\section{Apresentação e Análise dos Resultados}

Para extração de fatores, foi utilizada a análise de componentes principais com rotação oblíqua Promax, adequada para estudos na área de Ciências Sociais (Hair et al., 2005), e carga fatorial mínima de 0,4 As análises realizadas para testar o ajuste entre os dados e a análise fatorial foram as mesmas do pré-teste. 


\section{Análise descritiva da escala de Jeitinho e Sociedade Relacional}

A estrutura fatorial para o Jeitinho resultou em uma solução com três fatores (dimensões), explicando 63,6\% da variância total. O KMO foi de 0,851 e o teste de esfericidade de Bartlett mostrou a existência de correlações não nulas $(\mathrm{p}=0,0000)$. O detalhamento das cargas fatoriais, médias e o desvio padrão são exibidos na Tabela 1. Em cada dimensão, apresenta-se o alfa de Cronbach, a confiabilidade composta e a variância extraída. A confiabilidade composta foi calculada apenas para fins de avaliação complementar da confiabilidade, mas, no contexto de escalas somadas, o alfa de Cronbach é a medida mais adequada.

Tabela 1

\section{Dimensões da Escala Jeitinho}

\begin{tabular}{|c|c|c|c|}
\hline Percebo que na empresa em que trabalho... & $\begin{array}{c}\text { Carga } \\
\text { Fatorial }\end{array}$ & Média & $\begin{array}{l}\text { Desvio } \\
\text { Padrão }\end{array}$ \\
\hline \multicolumn{4}{|l|}{ Dimensão 1: Contorno de regras $(A=0,73\|C C=0,83\| V E=0,55)$} \\
\hline ... as pessoas flexibilizam as normas quando necessário. & 0,846 & 3,91 & 1,19 \\
\hline ... as regras são contornadas, dependendo da situação. & 0,773 & 3,76 & 1,22 \\
\hline ... entre o Sim e o Não, o Pode e o Não Pode, sempre existe um Talvez. & 0,702 & 4,02 & 1,11 \\
\hline $\begin{array}{l}\text {... para atendimento de um pedido de ajuda, eventualmente, alguma regra é } \\
\text { contornada. }\end{array}$ & 0,573 & 3,52 & 1,14 \\
\hline
\end{tabular}

\begin{tabular}{|c|c|c|c|}
\hline \multicolumn{4}{|l|}{ Dimensão 2: Flexibilização $(A=0,73$ || CC = 0,85 \| VE = 0,65) } \\
\hline $\begin{array}{l}\text {... é necessário ter jogo de cintura já que as normas não são adequadas a todas } \\
\text { as situações do dia a dia. }\end{array}$ & 0,870 & 3,97 & 1,25 \\
\hline $\begin{array}{l}\text {... frente a uma situação especial, é necessário contornar alguma regra para que } \\
\text { seja encontrada uma saída. }\end{array}$ & 0,869 & 3,82 & 1,17 \\
\hline ... para o bom andamento dos trabalhos, algumas regras são flexibilizadas. & 0,535 & 3,94 & 1,14 \\
\hline \multicolumn{4}{|c|}{ Dimensão 3: Estratégia informal de resolução de problemas $(A=0,59 \| C C=0,83$ || VE = 0,71) } \\
\hline ... resolver os problemas é mais importante que seguir as normas. & 0,883 & 3,22 & 1,17 \\
\hline $\begin{array}{l}\text {... em situações especiais, para solucionar problemas, faz-se necessário dar um } \\
\text { jeitinho. }\end{array}$ & 0,631 & 3,30 & 1,21 \\
\hline
\end{tabular}

Nota. $\mathrm{A}=$ Alfa de Cronbach; $\mathrm{CC}=$ Confiabilidade composta calculada a partir das cargas fatoriais obtidas na análise de componentes principais de cada dimensão em separado. VE = Variância extraída na análise de componentes principais de cada dimensão em separado.

As três dimensões apresentaram validade convergente (variância extraída superior a 0,5, conforme Hair et al., 2005) e confiabilidade acima do valor recomendado $(0,7)$, com exceção do da terceira dimensão, que apresentou um alfa de 0,59 , mas confiabilidade composta de 0,83 . Como esta dimensão foi mensurada por apenas dois itens, a única forma de melhorar a sua confiabilidade, medida pelo alfa de Cronbach, é aumentar a quantidade de itens em pesquisas futuras.

O Jeitinho, em contorno de regras, na primeira dimensão, inclui também a ideia de ambiguidade (entre o Sim e o Não, o Pode e o Não Pode, sempre existe um Talvez). A segunda dimensão remete à flexibilização, ou seja, a necessidade de ter jogo de cintura. Já a terceira dimensão, nomeada de estratégia informal de resolução de problemas, revela um raciocínio no qual seguir regras é menos importante que resolver os problemas. 
Convém observar que há uma concentração de respostas nas posições discordo pouco e concordo pouco. No entanto, o percentual de concordância é superior ao de discordância, revelando que os respondentes percebem a prática do Jeitinho na organização pesquisada.

A análise para as questões de Sociedade Relacional resultou em uma solução com quatro dimensões, explicando 55,3\% da variância total. O KMO foi de 0,693 e o teste de esfericidade de Bartlett mostrou a existência de correlações não nulas $(\mathrm{p}=0,0000)$. $\mathrm{O}$ detalhamento das cargas fatoriais, médias e desvio padrão são exibidos na Tabela 2. Em cada dimensão apresenta-se o alfa de Cronbach, a confiabilidade composta e a variância extraída.

Tabela 2

\section{Dimensões da Escala Sociedade Relacional}

\begin{tabular}{|c|c|c|c|}
\hline Percebo que na empresa em que trabalho... & $\begin{array}{c}\text { Carga } \\
\text { Fatorial }\end{array}$ & Média & $\begin{array}{l}\text { Desvio } \\
\text { Padrão }\end{array}$ \\
\hline \multicolumn{4}{|l|}{ Dimensão 1: Pessoalidade $(A=0,63\|C C=0,76\| V E=0,35)$} \\
\hline $\begin{array}{l}\text {... os relacionamentos profissionais tendem a se tornar relacionamentos } \\
\text { pessoais. }\end{array}$ & 0,676 & 3,48 & 1,12 \\
\hline$\ldots$ as pessoas estabelecem relações pessoais entre seus pares no trabalho. & 0,672 & 4,36 & 1,03 \\
\hline $\begin{array}{l}\text {... com o tempo, a confiança tende a substituir a impessoalidade na relação } \\
\text { profissional. }\end{array}$ & 0,633 & 3,86 & 1,11 \\
\hline$\ldots$ as pessoas buscam uma proximidade pessoal com seu chefe. & 0,547 & 3,97 & 1,08 \\
\hline ... as pessoas procuram trabalhar principalmente com quem simpatizam. & 0,425 & 3,83 & 1,39 \\
\hline $\begin{array}{l}\ldots \text { as pessoas produzem melhor quando trabalham em um grupo em que ocorre } \\
\text { proximidade no relacionamento pessoal dos membros. }\end{array}$ & 0,403 & 4,80 & 1,03 \\
\hline
\end{tabular}

\begin{tabular}{llll}
\hline Dimensão 2: Relações afetivo/familiares $(\mathbf{A}=\mathbf{0 , 6 6}\|\mathbf{C C}=\mathbf{0 , 8 6}\| \mathbf{V E}=\mathbf{0 , 7 6})$ & & \\
\hline ... o ambiente de trabalho se assemelha a um ambiente familiar. & 0,854 & 3,25 & 1,32 \\
... há um clima de afetividade entre os colegas de trabalho. & 0,831 & 4,24 & 0,96 \\
\hline
\end{tabular}

Dimensão 3: Predominância da confiança sobre as relações impessoais $(\mathrm{A}=0,56\|\mathrm{CC}=0,82\| \mathrm{VE}=$ 0,69)

\begin{tabular}{llll}
\hline$\ldots$ as relações de trabalho baseiam-se principalmente na confiança. & 0,815 & 4,16 & 1,09 \\
$\begin{array}{l}\text {... as relações de trabalho são baseadas mais na confiança que no } \\
\text { profissionalismo. }\end{array}$ & 0,777 & 3,42 & 1,12
\end{tabular}

\begin{tabular}{|c|c|c|c|}
\hline \multicolumn{4}{|c|}{$\begin{array}{l}\text { Dimensão 4: Predominância do relacionamento pessoal sobre o profissional }(\mathrm{A}=0,48\|\mathrm{CC}=0,79\| \mathrm{VE} \\
=0,66)\end{array}$} \\
\hline to pessoal é m & 0,797 & 3,36 & 1,18 \\
\hline $\begin{array}{l}\text {... um bom relacionamento pessoal com o chefe é mais importante que um bom } \\
\text { relacionamento profissional. }\end{array}$ & 0,719 & 3,17 & 1,22 \\
\hline
\end{tabular}

Nota. $\mathrm{A}=$ Alfa de Cronbach; $\mathrm{CC}=$ Confiabilidade composta calculada a partir das cargas fatoriais obtidas na análise de componentes principais de cada dimensão em separado. VE = Variância extraída na análise de componentes principais de cada dimensão em separado.

As dimensões da escala sociedade relacional apresentaram validade convergente (variância extraída superior a 0,5, conforme Hair et al., 2005), com exceção da primeira dimensão, em que todos os itens apresentaram cargas fatoriais inferiores a 0,7 quando foi realizada a análise de componentes principais destes itens em separado. Esse resultado pode ter ocorrido porque os seis itens abrangem diferentes conteúdos do domínio de definição do construto, assim uma diminuição da validade 
convergente é compensada por uma maior validade de conteúdo (Little, Lindengerger, \& Nesselroade, 1999).

Em relação à confiabilidade, as dimensões 3 e 4 apresentaram alfa de Cronbach abaixo de 0,6 (Tabela 2). Enquanto a confiabilidade composta superou o valor de 0,7 . Como ocorreu na escala do Jeitinho, recomenda-se em pesquisas futuras, aumentar a quantidade de itens nas dimensões que foram mensuradas por apenas dois itens.

A primeira dimensão retrata o primado da pessoalidade no ambiente de trabalho e diz respeito aos relacionamentos profissionais que tendem a se tornar relacionamentos pessoais, com pares e chefes. Com isso, a confiança tende a substituir a impessoalidade na relação profissional sendo o trabalho mais produtivo quando realizado com pessoas com as quais há um relacionamento pessoal. A segunda dimensão revela a necessidade de manter, no trabalho, relacionamentos baseados na afetividade, em situações que supostamente poderiam ser pautadas pela impessoalidade. A terceira dimensão traduz a predominância da confiança, originada das relações pessoais, sobre as relações impessoais. Finalmente, a quarta dimensão reflete o predomínio do relacionamento pessoal sobre o profissional.

\section{Análise das hipóteses}

Para a verificação das hipóteses de comparação entre os traços de Jeitinho e Sociedade Relacional e as variáveis Sexo, Idade, Cargo, Escolaridade e Tempo de Empresa, foram calculadas duas variáveis que consistiram nas médias, para cada respondente, dos itens de Jeitinho e dos itens de Sociedade Relacional. Esse procedimento, chamado de escala somada ou múltipla (DeVellis, 2003; Hair et al., 2005), baseia-se na interpretação dos fatores cuja identificação da dimensionalidade das variáveis indicou um relacionamento com a definição conceitual. Após verificação da premissa de confiabilidade da escala, o valor gerado (média) pode ser usado em várias análises como, por exemplo, em testes de comparação de médias (Brown, 2002, 2011).

Embora Jeitinho e Sociedade Relacional sejam multidimensionais, seus escores foram calculados como média de todos os itens de suas dimensões diretamente, em vez de calcular os escores médios para cada dimensão e, posteriormente, usar esses escores para calcular novos escores médios. Dessa forma, obteve-se um único escore para cada um dos traços, que foi usado na verificação das hipóteses 1 e 2 . Para isso, foram realizados dez testes de comparação entre médias, resultantes da combinação entre as escalas somadas de Jeitinho e Sociedade Relacional e as cinco variáveis sociodemográficas.

A técnica utilizada para a comparação entre as médias foi a ANOVA (Hair et al., 2005). Foram atendidos os pressupostos exigidos de normalidade e homocedasticidade por meio dos testes de Kolmogorov-Smirnov e do teste de homogeneidade de variância pela estatística de Levene, para cada uma das categorias das variáveis sociodemográficas acima mencionadas. O nível de significância adotado foi de $5 \%$.

Os resultados do teste ANOVA indicaram pela não rejeição da hipótese 1 e 2 de igualdade de médias das várias categorias dentre as variáveis pesquisadas. Os níveis de significância ( $p$-value) para Jeitinho foram: Sexo $(0,190)$, Idade $(0,480)$, Cargo $(0,343)$, Escolaridade $(0,982)$ e Tempo de empresa $(0,238)$. E para Sociedade Relacional foram: Sexo $(0,760)$, Idade $(0,233)$, Cargo $(0,328)$, Escolaridade $(0,596)$ e Tempo de empresa $(0,975)$. Desse modo, os respondentes, independente do sexo, idade, escolaridade, tempo de empresa e cargo, percebem o uso do Jeitinho no seu cotidiano de trabalho (hipótese 1) e a existência de um ambiente típico de uma Sociedade Relacional que condicione as relações no trabalho (hipótese 2). Esses resultados confirmam os achados de Barbosa (2006) em sua pesquisa sobre Jeitinho, em que a autora constatou o caráter universal do construto. Todos os pesquisados eram usuários do Jeitinho, independentemente de seu status sociodemográfico. Os achados também revelaram o caráter homogêneo na interpretação dos itens da escala de Sociedade Relacional, independentemente das características individuais ou funcionais dos respondentes.

Para a análise da Hipótese 3, procedeu-se primeiramente à análise do Alfa de Cronbach separadamente para as três dimensões do Jeitinho e as quatro dimensões da Sociedade Relacional, 
visando somar os itens de cada uma e realizar a análise de correlação. A dimensão Predominância do relacionamento pessoal sobre o profissional da escala Sociedade Relacional obteve um Alfa abaixo do recomendado $(0,484)$ e não foi usada na análise de correlação.

Tabela 3

Coeficiente de Correlação de Pearson entre as Dimensões de Jeitinho e Sociedade Relacional

\begin{tabular}{lccc}
\cline { 2 - 4 } & Pessoalidade & $\begin{array}{c}\text { Relações afetivo- } \\
\text { familiares }\end{array}$ & $\begin{array}{c}\text { Predominância } \\
\text { da confiança } \\
\text { sobre as relaçóes } \\
\text { impessoais }\end{array}$ \\
\hline Contorno de regras & $0,346^{* *}$ & 0,065 & $0,254^{* *}$ \\
Flexibilização & $0,282^{* *}$ & 0,026 & 0,104 \\
Estratégia Informal de Resolução de problemas & $0,302^{* *}$ & 0,008 & $0,150^{* *}$ \\
\hline
\end{tabular}

Nota. ** Correlação significante no nível de 0,01 .

Pela Tabela 3, observam-se que as três dimensões do Jeitinho se correlacionam com a dimensão Pessoalidade de Sociedade Relacional. Fundamentado na definição conceitual adotada para Jeitinho e Sociedade Relacional, isso significa que quanto maior a concordância que: os relacionamentos profissionais tendem a se tornar pessoais, que as pessoas estabelecem esses relacionamentos entre seus pares e chefes no trabalho, que a confiança tende, com o passar do tempo, a substituir a impessoalidade na relação profissional e as pessoas preferem trabalhar com quem simpatizam; maior tenderá a ser a concordância de contornar as regras, de ter jogo de cintura, pois as normas não são adequadas às situações rotineiras e resolver problemas é mais importante do que seguir estritamente as normas.

As relações afetivo-familiares de Sociedade Relacional não apresentaram correlações estatisticamente significativas com nenhuma dimensão do Jeitinho. Esse resultado causou surpresa, pois seria de esperar que um ambiente familiar e um clima de afetividade com colegas poderiam criar um ambiente facilitador para incidência do Jeitinho, baseado na literatura sobre as raízes da cultura brasileira, base para o desenvolvimento dos itens da escala. Cientistas sociais brasileiros ressaltam a cordialidade como traço característico de nossa sociedade. Holanda (1995) propôs o que tornou um arquétipo de brasilidade (Duarte, 2011) - o homem cordial. Freyre (2004) traça a raiz histórica do homem cordial à família patriarcal, representativa do Brasil colônia, onde "laços de sangue e de coração" (Holanda, 1995, p. 146) uniam simbolicamente senhores de engenho e escravos. A faceta cordial do Brasileiro é uma consequência de uma forma de interagir com o ambiente socioeconômico (Holanda, 1995). A fim de sobreviver a um sistema social oligárquico, o brasileiro desenvolveu o "jogo de cintura" - uma "flexibilidade de corpo e espírito para desviar-se de obstáculos - um aspecto que pode ser identificado como chave para o comportamento do brasileiro, o jeitinho" (Amado \& Brasil, 1991, p. $54)$.

Finalmente, na dimensão de Sociedade Relacional, a predominância da confiança sobre as relações impessoais obteve correlação significativa com necessidade de contornar as regras e a compreensão de que resolver problemas é mais importante do que seguir estritamente as normas. Interpreta-se que, quanto mais as relações pessoais predominam sobre a impessoalidade, maior deve ser a possibilidade de aplicar e receber o Jeitinho.

\section{Discussão dos Resultados}

O presente artigo adotou uma abordagem emic, pois partiu da descrição de características culturais típicas da sociedade brasileira para conceituar os traços de Jeitinho e Sociedade Relacional. Os 
resultados da pesquisa permitiram concluir que o Jeitinho é reconhecido e utilizado no âmbito da instituição financeira pesquisada.

O Jeitinho confirmou ser um construto formado pelas dimensões: contorno de regras, flexibilização e estratégia informal de solução de problemas. Os achados de Duarte (2011) destacam o uso estratégico de charme e simpatia, para estabelecer ou ampliar as relações pessoais. Duarte ilustrou três dimensões interconectadas do Jeitinho, muito próximas das identificadas nesta pesquisa: o jeitinho como uma forma brasileira percebida de ser; como um estilo brasileiro criativo de solução de problemas; e como uma prática radical que requer contornar ou quebrar regras para conseguir obter algo realizado.

Outras pesquisas também confirmam a multidimensionalidade do Jeitinho. DaMatta (1984) considera que o Jeitinho está intimamente associado com a malandragem e, consequentemente, com a transgressão às leis e a desonestidade, mas também considera a existência do Jeitinho positiva (DaMatta, 2009), que não causa danos a outro. A pesquisa de Barbosa (2006) revelou que no nível da representação simbólica as pessoas distinguem claramente o significado de favor, Jeitinho e corrupção. No entanto, nas interações sociais concretas, ressalta a autora, os brasileiros têm dificuldade em distinguir esses três mecanismos sociais. Ferreira, Fischer, Porto, Pilati e Milfont (2012) usaram uma abordagem de cenário e demonstraram que tal traço pode ser descrito por uma estrutura de três dimensões: corrupção, criatividade e quebra de normas sociais. Pilati, Milfont, Ferreira, Porto e Fischer (2011) entendem o traço como uma estratégia de influência social para resolução de problemas, também encontrado na presente pesquisa.

$\mathrm{Na}$ literatura estrangeira, alguns autores entendem o Jeitinho como uma prática social próxima ao favor, lado a lado de Guanxi, (China), Blat/Sviazi (Rússia) e Jaan-pehchaan (Índia) (McCarthy et al., 2012; Puffer, McCarthy, \& Peng, 2013), principalmente em países de estágio econômico em desenvolvimento, como os BRIC (Brasil, Rússia, Índia e China). Nesse caso, esses conceitos são compreendidos como nativos, enraizados na cultura local, socialmente aceitos e eficazes na realização de negócios e resultados, na medida em que se constituem numa instituição cognitivo-cultural informal (McCarthy et al., 2012). Todavia, à luz dos países desenvolvidos e de predominância cultural individualista, tais estratégias podem significar não éticas (McCarthy\& Puffer, 2008).

Esses achados empíricos apontam que o Jeitinho é um conceito difuso, a despeito de ser visto como sinônimo de nossa identidade nacional (Barbosa, 2006). Contudo, as pesquisas mostram que a utilização do Jeitinho é praticamente uma necessidade de sobrevivência em face da dificuldade do brasileiro de relacionar-se com leis e regras, devido ao excessivo formalismo da sociedade brasileira.

Os testes estatísticos aplicados na análise da hipótese 1 não rejeitaram a igualdade na utilização do Jeitinho, indistintamente do sexo, idade, cargo, escolaridade e tempo de casa. Esse achado mostra a universalidade do traço, pois é "pensado como algo utilizado por todos na sociedade brasileira" (Barbosa, 2006, p. 40). Da mesma forma, observou-se que, independentemente das variáveis sociodemográficas, as características de Sociedade Relacional se mostraram presentes na organização pesquisada (hipótese 2).

Também contribuem para o Jeitinho as características de Sociedade Relacional, da busca por intimidade, da aversão ao confronto, as quais se inter-relacionam e permitem sua existência (Motta \& Alcadipani, 1999). Outra característica marcante da nossa sociedade é a cordialidade do brasileiro, sua afabilidade, hospitalidade e generosidade (Holanda, 1995).

Os achados obtidos nesta pesquisa estão em linha com as características acima mencionadas. A correlação entre as três dimensões do Jeitinho e as dimensões Pessoalidade e Predominância da confiança sobre as relações impessoais de Sociedade Relacional evidenciam o estabelecimento de relações pessoais com pares e chefias, e relacionamentos profissionais que tendem a tornarem-se pessoais, podendo inferir que isso cria um ambiente favorável à utilização do Jeitinho nas áreas pesquisadas da organização. Essa constatação corrobora a Hipótese 3. 


\section{Considerações Finais}

Como abordado no referencial teórico, pesquisas empíricas sobre traços da cultura brasileira são predominantemente qualitativas. Recentemente surgiram instrumentos desenvolvidos por pesquisadores oriundos da psicologia social para mensurar o Jeitinho. Outra característica é que os respondentes nem sempre foram identificados como profissionais de empresas.

Realizar uma pesquisa quantitativa em um ambiente organizacional formal acerca de Jeitinho e Sociedade Relacional acarreta alguns desafios. A pesquisa pode gerar algum desconforto ao respondente, à medida que suscita uma reflexão a respeito de burlar certas regras ou assumir a sobreposição do relacionamento pessoal sobre o profissional. Procurou-se minimizar tal situação, desviando o foco dos itens para os outros, ou seja, se o respondente percebe a existência de práticas que denotem Jeitinho e Sociedade Relacional. O maior nível de discordância referiu-se à percepção de que um bom relacionamento pessoal com o chefe é mais importante que um bom relacionamento profissional. O maior nível de concordância referiu-se à percepção de que as pessoas produzem melhor quando trabalham em um grupo em que ocorre proximidade no relacionamento pessoal dos membros. Considerando isoladamente esses dois itens, depreende-se que o relacionamento com os pares denota ser mais importante que a ligação com o superior hierárquico.

As pessoas tenderam a rejeitar mais os itens que abordam posicionamentos diretos (p.ex.: "em situações especiais, para solucionar problemas, faz-se necessário 'dar um jeitinho'"), do que assertivas de conteúdos relativos à necessidade de flexibilização. Isso denuncia o aspecto negativo associado à ação de dar um Jeitinho e uma faceta mais positiva quando diz respeito à flexibilização, ou seja, ter jogo de cintura e encontrar uma saída, visando um bom andamento do trabalho. O primeiro aparenta ser um recurso não muito apreciado, enquanto o segundo expressa uma habilidade praticada para resolver os problemas cotidianos.

As implicações teóricas desse estudo consistem em promover o uso de abordagem de gerenciamento indígena (indigenous management), isto é, desenvolver constructos a partir da cultura local. Isso implica refletir criticamente sobre a apropriação de práticas universais e globais concebidas em países com diferentes características culturais, principalmente nos Estados Unidos. Nesta linha de raciocínio, encontram-se estudos de Alcadipani, Khan, Gantman e Nkomo (2012) e Alcadipani e Rosa (2011). Estes autores promovem uma reflexão crítica sobre uma visão predominantemente anglosaxônica de gestão vis-à-vis, uma abordagem de gestão desenvolvida a partir do conhecimento local.

Reconhecer as diferenças culturais implica conhecer e comparar as diferenças. Nesse sentido, estudos em cross-cultural tornam-se cada vez mais relevantes para compreender aspectos da gestão que revelem as diferenças culturais. Para isso, as escalas de Jeitinho e Sociedade Relacional contribuem para o avanço da compreensão teórica desses constructos, ao aplicar em diferentes países e verificar empiricamente sua natureza local e indígena.

Além disso, como contribuição ao campo dos estudos organizacionais, as escalas de Jeitinho e Sociedade Relacional podem ser aplicadas em investigações como variáveis independentes ou moderadoras, para a compreensão de fenômenos que podem sofrer influências da cultura brasileira. $\mathrm{Ou}$, ainda, como variáveis dependentes, buscando-se entender quais fenômenos explicam esses dois traços. À medida que essas relações forem sendo comprovadas, seria possível avançar na direção de uma abordagem indígena de gestão, culturalmente contextualizada.

As implicações práticas desses resultados remetem a uma reflexão sobre as eventuais consequências para as organizações com a prática do Jeitinho, sejam positivas ou não. As escalas de Jeitinho e Sociedade Relacional podem ser utilizadas como um instrumento para diagnosticar a presença desses traços na cultura da empresa e suas possíveis relações com outras práticas organizacionais.

Como limitação, salienta-se o fato de a pesquisa ter sido realizada em uma amostra não probabilística de uma única organização, especificamente em sua sede administrativa. Portanto, os 
resultados não podem ser generalizados. As escalas de Jeitinho e Sociedade Relacional precisam ser testadas em amostras mais heterogêneas, constituídas por organizações de diferentes setores e porte, estatais e públicas, origem e regiões geográficas do Brasil. Pesquisas também poderiam ser endereçadas para verificar se empresas com código de conduta ou de integridade apresentam resultados diferentes das que não possuem tais códigos. Por fim, para melhorar a confiabilidade das escalas, sugere-se aumentar o número de itens de Jeitinho e Sociedade Relacional.

\section{Agradecimentos}

Os autores agradecem os comentários valiosos do Prof. Diógenes de Souza Bido e aos avaliadores anônimos pelos comentários construtivos nas versões anteriores do artigo.

\section{Referências}

Abreu Vieira, C., Costa, F. L. da, \& Barbosa, L. O. (1982). O jeitinho brasileiro como recurso de poder. Revista de Administração Pública, 16(2), 05-31.

Alcadipani, R., \& Crubellate, J. M. (2003). Cultura organizacional: generalizações improváveis e conceituações imprecisas. Revista de Administração de Empresas, 43(2), 64-76. doi: 10.1590/S0034-75902003000200005

Alcadipani, R., Khan, F. R., Gantman, E., \& Nkomo, S. (2012). Southern voices in management and organization knowledge. Organization, 19(2), 131-143. doi: 10.1177/1350508411431910

Alcadipani, R., \& Rosa, A. R. (2011). From global management to glocal management: Latin American perspectives as a counter-dominant management epistemology. Canadian Journal of Administrative Sciences, 28(4), 453-466. doi: 10.1002/cjas.165

Almeida, A. C. (2007). A cabeça do brasileiro. Rio de Janeiro: Record.

Amado, G., \& Brasil, H. V. (1991). Organizational behaviors and cultural context: the Brazilian jeitinho. International Studies of Management \& Organization, 21(3), 38-61.

Balbinot, Z., Minghini, L., \& Borim-de-Souza, R. (2012). Indigenous Brazilian management practices. Journal of Technology Management \& Innovation, 7(4), 132-147. doi: 10.4067/S071827242012000400011

Barbosa, L. N. H. (1987). O jeitinho brasileiro: um estudo de identidade nacional (Tese de doutorado). Universidade Federal do Rio de Janeiro, Rio de Janeiro, RJ, Brasil.

Barbosa, L. N. H. (1996). Cultura administrativa: uma nova perspectiva das relações entre Antropologia e Administração. Revista de Administração de Empresas, 36(4), 6-19. doi: 10.1590/S003475901996000400002

Barbosa, L. N. H. (2006). O jeitinho brasileiro: a arte de ser mais igual do que os outros (2a ed.). Rio de Janeiro: Campus.

Barros, B. T. (2003). Gestão à brasileira: somos ou não diferentes? Uma comparação com América Latina, Estados Unidos, Europa e Ásia. São Paulo: Atlas.

Barros, B. T., \& Prates, M. A. S. (1996). O estilo brasileiro de administrar. São Paulo: Atlas. 
Berry, J. W., Poortinga, Y. H., Segall, M. H., \& Dasen, P. R. (2002). Psychology and the majority world. In J. W Berry, Y. H. Poortinga, M. H. Segall, \& P. R. Dasen, Cross-cultural psychology: research and application (pp. 456-471). New York: Cambridge University Press.

Brown, J. D. (2002). The Cronbach alpha reliability estimate. SHIKEN: JALT Testing \& Evaluation SIG Newsletter, 6(1), 17-19. Retrieved from http://jalt.org/test/PDF/Brown13.pdf

Brown, J. D. (2011). Likert items and scales of measurement? SHIKEN: JALT Testing \& Evaluation SIG Newsletter, 15(1), 10-14. Retrieved from http://jalt.org/test/PDF/Brown34.pdf

Campos, R. O. (1976). A sociedade do jeito. In R. O. Campos (Ed.), A técnica e o riso (pp. 17-21). Rio de Janeiro: Edições Apec.

Chu, R. A. (2010). Modelo contemporâneo da gestão à brasileira. São Paulo: Cengage Learning.

Chu, R. A., \& Wood, T., Jr. (2008). Cultura organizacional brasileira pós-globalização: global ou local? Revista de Administração Pública, 42(5), 969-991.

DaMatta, R. (1978). Carnavais, malandros e heróis: para uma sociologia do dilema brasileiro. Rio de Janeiro: Rocco.

DaMatta, R. (1984). O que faz o Brasil, Brasil? Rio de Janeiro: Rocco.

DaMatta, R. (2009). O jeitinho brasileiro é uma forma de corrupção? Revista de História, 42. Recuperado de http://www.revistadehistoria.com.br/secao/conteudo-complementar/forum-sobrecorrupcao-roberto-damatta

DeVellis, R. F. (2003). Scale development theory and applications. California: SAGE Publications.

Duarte, F. (2006). Exploring the interpersonal transaction of the Brazilian jeitinho in bureaucratic contexts. Organization, 13(4), 509-527.

Duarte, F. (2011). The strategic role of charm, simpatia and jeitinho in Brazilian society: a qualitative study. Asian Journal of Latin American Studies, 24(3), 29-48. doi: 10.1177/1350508406065103

Ferreira, M. C., Fischer, R., Porto, J. B., Pilati, R., \& Milfont, T. L. (2012). Unraveling the mystery of Brazilian jeitinho: a cultural exploration of social norms. Personality and Social Psychology Bulletin, 38(3), 331-344. doi: 10.1177/0146167211427148

Freitas, A. B. (1997). Traços brasileiros para uma análise organizacional. In F. C. P. Motta \& M. P. Caldas (Orgs.), Cultura organizacional e cultura brasileira (pp. 38-54). São Paulo: Atlas.

Freyre, G. (2004). Casa grande \& senzala: formação da família brasileira sob o regime da economia patriarcal (49a ed.). São Paulo: Global.

Hair, J. F., Anderson, R. E., Tathan, R. L., \& Black, W. C. (2005). Análise multivariada de dados. Porto Alegre: Bookman.

Holanda, S. B. de (1995). Raízes do Brasil. São Paulo: Cia das Letras.

Houaiss, A. (n.d.). Dicionário Houaiss da língua portuguesa. Recuperado de http://houaiss.uol.com.br/busca?palavra=indigena

Little, T. D., Lindengerger, U., \& Nesselroade, J. R. (1999). On selecting indicators for multivariate measurement and modeling with latent variables: when "good" indicators are bad and "bad" indicators are good. Psychological Methods, 4(2), 192-211. doi: 10.1037//1082-989X.4.2.192 
MacKenzie, S. B., Podsakoff, P. M., \& Jarvis, C. B. (2005). The problem of measurement model misspecification in behavioral and organizational research and some recommended solutions. Journal of Applied Psychology, 90(4), 710-730. doi: 10.1037/0021-9010.90.4.710

McCarthy, D. J., \& Puffer, S. M. (2008). Interpreting the ethicality of corporate governance decisions in Russia: utilizing integrative social contracts theory to evaluate the relevance of agency theory norms. Academy of Management Review, 33(1), 11-31. doi: 10.5465/AMR.2008.27745006

McCarthy, D. J., Puffer, S. M., Dunlap, D. R., \& Jaeger, A. M. (2012). A stakeholder approach to the ethicality of BRIC-firm managers' use of favors. Journal of Business Ethics, 109(1), 27-38. doi: 10.1007/s10551-012-1377-4

Motta, F C. P. (1997). Cultura e organizações no Brasil. In F. C. P. Motta \& M. P. Caldas (Orgs.), Cultura organizacional e cultura brasileira (pp. 25-37). São Paulo: Atlas.

Motta, F. C. P., \& Alcadipani, R. (1999). Jeitinho brasileiro, controle social e competição. Revista de Administração de Empresas, 39(1), 6-12. doi: 10.1590/S0034-75901999000100002

Motta, F. C. P., \& Bresser Pereira, L. C. (1984). Introdução à organização burocrática. São Paulo: Brasiliense.

Netemeyer, R. G., Bearden, W. O., \& Sharma, S. (2003). Scaling procedures: issues and applications. Thousand Oaks: Sage Publications.

Pilati, R. R., Milfont, T. L., Ferreira, M. C., Porto, J., \& Fischer, R. (2011). Brazilian jeitinho: understanding and explaining an indigenous psychological construct. Interamerican Journal of Psychology, 45(1), 29-38.

Podsakoff, P. M., MacKenzie, S. B., Lee, J.-Y., \& Podsakoff, N. P. (2003). Common method biases in behavioral research: a critical review of the literature and recommended remedies. The Journal of Applied Psychology, 88(5), 879-903. doi: 10.1037/0021-9010.88.5.879

Prado, M. C. A. B. (2005). Jeitinho e cultura organizacional brasileira - ultrapassando a abordagem de integração (Relatório de pesquisa n. 25/2005), São Paulo, SP, GVPesquisa, Escola de Administração de Empresas, Fundação Getúlio Vargas.

Puffer, S. M., McCarthy, D. J., \& Peng, M. W. (2013). Managing favors in a global economy. Asia Pacific Journal of Management, 30(2), 321-326. doi: 10.1007/s10490-012-9340-6

Ramos, A. G. (1966). Administração e estratégia do desenvolvimento: elementos de uma sociologia especial da administração. Rio de Janeiro: Ed. da Fundação Getúlio Vargas.

Ramos, A. G. (1983). Administração e contexto brasileiro. Rio de Janeiro: Ed. da Fundação Getúlio Vargas.

Ribeiro, D. (2006). O povo brasileiro. São Paulo: Cia das Letras.

Rosenn, K. (1971). The jeito: Brazil's institutional by-pass of the formal legal system and its development implications. The American Journal of Comparative Law, 19(3), 516-549. doi: $10.2307 / 839559$

Sinha, D. (1997). Indigenizing psychology. In J. W. Berry, Y. H. Poortinga, \& J. Pandey (Eds.), Handbook of cross-cultural psychology (Vol. 1, 2nd ed., pp. 129-169). Boston: Ally \& Bacon.

Smith, P. B. (2008). Indigenous aspects of management. In P. B. Smith, M. F. Peterson, \& D. C. Thomas (Eds.), The handbook of cross-cultural management research (pp. 319-332). Thousand Oaks, CA: Sage Pub. 
Smith, P. B., Huang, H. J., Harb, C., \& Torres, C. (2012). How distinctive are indigenous way of achieving influence? A comparative study of guanxi, wasta, jeitinho, and pulling strings. Journal of Cross-Cultural Psychology, 43(1), 135-150. doi: 10.1177/0022022110381430

Torres, J. C. O. (1973). Interpretação da realidade brasileira. Rio de Janeiro: José Olympio

\section{Dados dos Autores}

Ricardo Antonio Fernandes

Rua da Consolação, 896, Consolação, 01302-907, São Paulo, SP, Brasil. E-mail: ricardo.fernandes@ mackenzie.br

Darcy Mitiko Mori Hanashiro

Rua da Consolação, 896, Consolação, 01302-907, São Paulo, SP, Brasil. E-mail: darcyhanashiro@ gmail.com 